\title{
Mulher e dor: um estudo na perspectiva da Psicodinâmica do Trabalho
}

\section{Woman and Pain: a study in the psychodynamic perspective of the work}

\section{Rubia Minuzzi Tschiedel*}

Universidade do Vale do Rio dos Sinos-UNISINOS, São Leopoldo, Rio Grande do Sul, Brasil

\section{Elisete Soares Traesel**}

Centro Universitário Franciscano-UNIFRA, Santa Maria, Rio Grande do Sul, Brasil

\begin{abstract}
RESUMO
O trabalho apresenta um estudo sobre o trabalho feminino considerando a dor e a somatização como expressões do sofrimento. Para alcançar os objetivos da pesquisa, foi efetuada uma pesquisa bibliográfica abordando, em especial, a articulação da temática com os fundamentos da psicodinâmica do trabalho e com as pesquisas sobre trabalho e gênero. Existe uma relação complexa que vincula a dor às vivências subjetivas e à identidade social. Da mesma forma, a ausência de espaços para discussão e visibilidade das contribuições da mulher impedem que haja uma reapropriação do significado do seu trabalho enquanto fonte de prazer, independência e realização.
\end{abstract}

Palavras-chave: Mulher, Dor, Somatização, Psicodinâmica do Trabalho.

\begin{abstract}
The paper presents a study on women's work considering the pain and somatization as expressions of suffering. To achieve the objectives of this research, a bibliographic research was made addressing, in particular, the articulation of the theme with the fundamentals of work psychodynamics and a research about work and gender.

There is a complex relationship that links the pain with the subjective experiences and social identity.

Likewise, the lack of discussion and visibility of woman's contributions refrains the reappropriation of the meaning of her work as a source of pleasure, independence and fulfillment.
\end{abstract}

Key-words: Woman, Pain, Somatization, Psychodynamic of work.

\section{Introdução}

O trabalho feminino, segundo Nogueira (2006), apresenta algumas características como à dupla jornada em que concomitante às 
atividades laborais, a mulher realiza o trabalho doméstico e o cuidado da família. E este, por não ser remunerado, é considerado ainda menos reconhecido, tornando-se uma atividade repetitiva, desgastante e sem sentido. Fonseca (2000) aponta que, mesmo que as mulheres demonstrem plenas condições de fazer o que lhes é atribuído, continuam hierarquicamente subordinadas ao domínio masculino, tendo seu trabalho desvalorizado até o limite do insuportável. Assim, para conquistar elevação funcional, as mulheres acabam indo além de suas forças para romper preconceitos e determinismos sociais e culturais relativos ao gênero. Desta forma, podemos perceber que a dor tende a se manifestar no corpo feminino, tão exigido pelo trabalho, como uma estratégia de defesa (DEJOURS, 1999/2004) no intuito de indicar que está havendo alguma condição de trabalho insuportável e que, no decorrer, poderá desorganizar este sujeito. Segundo Dejours e Abdoucheli (1994), o sofrimento que não pode ser transformado, que não encontra sentido, torna-se sofrimento patológico associado à desestabilização psíquica podendo levar ao desequilíbrio psíquico e somático. A dor pode ser, então, uma manifestação deste desequilíbrio, em que o corpo, tão pressionado pelas exigências contemporâneas à mulher, manifesta-se pedindo socorro e apontando a fadiga e a falta de realização e significado do trabalho. Nesta direção, o reconhecimento que, segundo Dejours (1999/2004) possibilitaria que o sofrimento encontrasse um sentido encontra-se extremamente limitado pela rotina e laborização do trabalho feminino na atualidade. Conforme Lancman (2004, p.33) "o desenvolvimento da identidade e a transformação do sofrimento estão diretamente relacionados ao olhar do outro e aos mecanismos de reconhecimento decorrentes deste olhar." Desta forma, ao não encontrar espaços de visibilidade, o sofrimento vivenciado pela mulher em seu trabalho, pode encontrar no corpo, na dor, na somatização o lugar para se expressar, levando ao adoecimento. Quando as estratégias de defesa coletivas falham pelo individualismo, surgem as patologias da solidão (DEJ OURS, 2004), sendo que a dor pode estar entre estas indicando que está havendo no trabalho uma condição insuportável que a mulher não está conseguindo transpor ou elaborar.

\section{Metodologia}

Escolheu-se a pesquisa bibliográfica, por acreditar-se que este método é o mais adequado para estudar o tema escolhido. Conforme Lakatos (1986), a pesquisa bibliográfica tem por objetivo conhecer as diferentes contribuições científicas disponíveis sobre determinado tema. Este estudo objetivou a catalogação de bibliografias publicadas acerca do tema. 
Conforme Gil (2002), a fundamental vantagem da pesquisa bibliográfica consiste no fato de permitir ao pesquisador a cobertura de uma série de fenômenos muito mais ampla do que aquela que poderia pesquisar diretamente. A pesquisa bibliográfica envolve etapas, iniciando pela escolha do tema, onde o pesquisador determina a temática de sua pesquisa. Passando a seguir, para um levantamento bibliográfico preliminar a fim de facilitar sua formulação do problema e, ao final desse levantamento, espera-se que o estudante esteja em condições de formular seu problema de pesquisa, pois somente a partir desta etapa terá condições de iniciar seu trabalho (GIL, 2002).

Com isso, elaborar-se-á um plano provisório de assunto para organizar sistematicamente as diversas partes que compõem o objeto de estudo. O passo seguinte, consiste na identificação das fontes capazes de fornecer as respostas pertinentes à solução do problema proposto. Para localizar as fontes, normalmente se utiliza a biblioteca, mas nada impede de utilizar-se de materiais bibliográficos em formatos eletrônicos (GIL, 2002).

Após a obtenção do material, passa-se a leitura do mesmo e esta, deve seguir os objetivos de identificar as informações e os dados constantes no material, estabelecer relações entre as informações e os dados obtidos com o problema proposto e, ainda, analisar a consistência das informações e dados apresentados pelos autores. Para que as informações lidas não se percam, é interessante a tomada de apontamentos, onde se toma notas do material lido. Após esta última etapa citada, procede-se à confecção das fichas de leitura para que se identifiquem as obras consultadas, registrem-se os conteúdos das obras e os comentários acerca das mesmas, ordenando os registros (GIL, 2002).

Para Gil (2002), a composição das fichas compreende três partes principais: cabeçalho, referência bibliográfica e texto. Sendo que o cabeçalho que é constituído pelos elementos de identificação das fichas, as referencias bibliográficas constituem os elementos indicadores da obra e o texto, que compõem o corpo das fichas e varia conforme sua finalidade. Por conseguinte, situa-se a construção lógica do trabalho que visa à organização das idéias com vista em atender aos objetivos ou testar hipóteses formuladas no início da pesquisa. E, por fim, a redação do relatório que se dá mais pelo estilo do autor, pois não há uma regra clara a ser adotada.

\section{0 sofrimento no trabalho}

Em relação à psicodinâmica do trabalho, Dejours (1999) aponta que o trabalho transita em um território ambivalente, uma vez que tanto pode dar origem a processos de alienação e mesmo de 
descompensação psíquica, como pode ser fonte de saúde e instrumento de emancipação.

O autor relata que o trabalho pressupõe não somente uma preocupação com a eficácia técnica, mas busca incorporar argumentos relativos ao viver em comum relativos ao mundo social do trabalho e de proteção e realização do ego, portanto, relativos à saúde e ao mundo subjetivo. Assim, o trabalho não é somente a execução de atividades produtivas, mas, também, é espaço de convivência.

Considera-se que saúde no trabalho não implica ausência de sofrimento, mas possibilidades internas e externas do sujeito de transformação das situações adversas, no movimento de busca de prazer e fuga do sofrimento (MENDES, 2004). Neste sentido, 0 trabalho pode ser transformado em prazer, quando percebe-se que o mesmo possibilita a aplicação da inteligência e a utilização desta não é contrariada e, ainda, quando se reconhece a importância da mesma para a organização do trabalho. O trabalho, assim, é percebido como saúde, pois as relações do mesmo se tornam mediadoras das realizações do sujeito e da construção da sua identidade (DEJOURS, 2004b).

E é de fundamental importância compreender as formas de organização social do trabalho e seus reflexos na qualidade de vida, bem como na saúde e na forma de adoecimento dos trabalhadores para assim perceber que situações estejam gerando agravos à sua saúde e sofrimento (HELOANI \& LANCMAN, 2004). A organização do trabalho é uma relação social, é um acordo entre objetivos e prescrições (procedimentos, maneira de organizar o trabalho, método) e as dificuldades reais para a realização do trabalho (DEJ OURS, 2004a).

Segundo Dejours (1992), quando a atividade do trabalhador é reconhecida e valorizada pela organização, o trabalho se torna estruturante na identidade do indivíduo, mas quando esta mesma atividade não é significativa para o sujeito, para a organização nem para a sociedade, ela pode ser fonte de sofrimento.

Para que o trabalho seja fonte de saúde, há necessidade do reconhecimento daquele que trabalha, uma vez que neste reconhecimento reside a possibilidade de transformar o sofrimento em prazer (DEJ OURS, 1999).

Quando se rompe o equilíbrio, o sofrimento não é mais contornável, surge a patologia, ou seja, não devemos confundir estado de normalidade com estado saudável. O estado de normalidade pode refletir um estado de equilíbrio entre as pessoas, mas também, ser um sintoma patológico, onde os sujeitos se esforçam para manteremse produtivos e atuantes mesmo à custa de muito sofrimento (LANCMAN \& UCHIDA, 2003). 
Para Dejours (1994), o paradoxo psíquico do trabalho suscita o tema equilíbrio ou fadiga pelo trabalho, onde fonte de equilíbrio para uns, é a causa de fadiga para outros. O trabalho equilibrante é aquele escolhido livremente, que se torna um meio de relaxamento e, após a tarefa terminada, o trabalhador sente-se melhor do que antes de ter começado. Já o trabalho fatigante é aquele onde a energia psíquica se acumula, não achando vias de descarga para suas necessidades, com isso, acumulando-se e tornando-se fonte de tensão, chegando à patologia.

Segundo Dejours (1994), o sofrimento promove estratégias defensivas, suscitando assim uma ideologia defensiva, onde seu caráter é vital, fundamental e necessário. A ideologia defensiva é funcional a nível de grupo, de sua coesão, de sua coragem, e é funcional também a nível do trabalho; é a garantia da produtividade (DEJ OURS, 1992). Esta surge substituindo os mecanismos de defesa individuais por estratégias coletivas de defesa, que agem sobre a percepção da realidade, tornando-a mais suave e, concedendo ao sujeito uma segurança que, apenas com suas próprias defesas, ele será incapaz de garantir (DEJ OURS, 1994).

A diferença fundamental entre um mecanismo de defesa individual e uma estratégia coletiva de defesa é que o mecanismo de defesa está interiorizado, ou seja, ele persiste mesmo sem a presença física de outros, enquanto a estratégia coletiva de defesa não se sustenta a não ser por um consenso, dependendo assim, de condições externas (DEJ OURS, ABDOUCHELI \& JAYET, 1994).

Para Mendes (1996), as estratégias defensivas são necessárias para a saúde do trabalhador enquanto protegem 0 sujeito contra 0 sofrimento causado pelas situações de trabalho geradoras de conflito e evitam o adoecimento, ainda que a condição necessária para o equilíbrio psíquico deste estaria na possibilidade do âmbito laboral ser um local de reconhecimento, liberdade e valorização do trabalhador. Em contrapartida, essas defesas tornam-se negativas quando alienam o indivíduo, imobilizando-o e não provocando mudanças no contexto de trabalho.

A utilização do conceito de Psicodinâmica do Trabalho em substituição ao de Psicopatologia do Trabalho, deu-se a partir do investimento no estudo da normalidade sobre o da patologia. Ao propor a normalidade como objeto, abre caminho para perspectivas mais amplas, que, como veremos, não abordam apenas o sofrimento, mas, ainda, o prazer no trabalho: não mais somente o homem, mas o trabalho; não mais apenas a organização do trabalho, mas as situações de trabalho nos detalhes de sua dinâmica interna (DEJ OURS, 2004a).

Quando falamos da normalidade, enquanto conseqüência de um compromisso entre o sofrimento e as estratégias de defesa, isso denota que no trabalho a normalidade supõe sempre a existência do sofrimento. Como aponta Dejours (1999, p.19), a normalidade é uma 
obtenção "mediante uma luta feroz entre as exigências do trabalho e a ameaça de desestabilização psíquica e somática". Dejours assevera que o sofrimento é, antes de tudo, um sofrimento do corpo: "não pode haver sofrimento sem carne" (1999, p. 19).

O sofrimento intermediaria a doença mental e o bem-estar psíquico, implicando em um estado de luta do sujeito contra as forças que o empurrariam a doença mental. A partir de então, o sofrimento passou a adquirir uma nova significação que abarcava elementos patológicos e criativos (DEJ OURS, 1994).

Dejours, Abdoucheli e Jayet (1994) descrevem o conceito de sofrimento criativo e sofrimento patológico. O sofrimento patológico é aquele onde não há nada além de vivências fixas, rígidas e inaugura a repetição, a frustração, o aborrecimento e sentimentos de impotência. Com isso, o trabalho se torna um mediador de desequilíbrio e fraqueza da saúde, destruindo o aparelho mental e a estabilidade psíquica do sujeito, levando-o para uma descompensação e para a doença. Já o sofrimento criativo é onde o trabalho propicia a sua transformação em criatividade e, conseqüentemente, em saúde. Assim, a contribuição do trabalhador à organização do trabalho beneficia as características do sujeito, aumentando a resistência do mesmo ao risco de um desequilibro psíquico ou somático.

Dejours (1992) aponta que o sofrimento psíquico sucedido da forma como o trabalho se organiza começa quando o trabalhador usou tudo que estava ao seu alcance em termos de conhecimento e de poder na organização do trabalho, e mesmo assim, ele não pode mais mudar nem sua tarefa, nem a forma como ela é feita. O conflito entre organização do trabalho e funcionamento psíquico pôde ser reconhecido como fonte de sofrimento, ao mesmo tempo como chave de sua possibilidade de análise.

Em contrapartida, conforme Dejours (1994/1999), o trabalho passa de sofrimento para prazer, quando a qualidade do trabalho é reconhecida e os desânimos e contradições adquirem sentido. Todo esse sofrimento não somente prestou uma contribuição à organização do trabalho, mas também, em compensação, fez do sujeito um ser diferente daquele que ele era antes do reconhecimento de sua contribuição.

Quanto à significação, Martins e Pinheiro (2006) relatam que o trabalho possui diferentes significados, mas, de forma geral, denota efetuar uma obra que expresse resultados, que ocasione reconhecimento social e permaneça além da vida, mas também é sinônimo de esforço repetitivo e rotineiro, sem liberdade, de efeito consumível e aborrecimento inevitável.

Para Brant e Minayo-Gomez (2004), atualmente, criou-se uma necessidade de banir o sofrimento do mundo do trabalho e desconsiderá-lo como uma dimensão contingente à produção. 
Entretanto, no âmbito da gestão do trabalho, se faz importante dar visibilidade ao processo de transformação do sofrimento em adoecimento, já que este pode discriminar, estigmatizar e excluir o trabalhador.

Esse sofrimento sendo transformado em adoecimento pode ser relacionado ao sofrimento patológico abordado por Dejours (1994). Segundo o autor, este desestabiliza psiquicamente o sujeito e pode levá-lo ao desequilíbrio psíquico e somático.

Conforme Brant e Minayo-Gomez (2004), existem várias maneiras de experimentar e manifestar o sofrimento, dentre elas estão à fala, sonhos, corpo, atos e pelo trabalho. É importante reconhecer que o que significa sofrimento para um não necessariamente será para outro, podendo, ainda haver dor e prazer simultaneamente.

O sofrimento também pode ser entendido quando experimentado o desgaste em relação ao trabalho, onde aparece a sensação de cansaço, desânimo e descontentamento no âmbito laboral (MARTINS $\&$ PINHEIRO, 2006).

Conforme Coelho e Ávila (2007), acredita-se que quando o indivíduo manifesta seus conflitos e angústias psicológicas através de sintomas corporais, ele o faz geralmente em resposta a estressores psicossociais como eventos de vida e situações conflitivas. Podemos pensar na questão do trabalho como sendo um estressor, local esse em que o indivíduo pode correr riscos físicos e situações estressantes que venham a colaborar no surgimento de sintomas somáticos. Nesse contexto, as condições de trabalho, ou seja, as circunstâncias sob as quais os indivíduos mobilizam as suas capacidades físicas, cognitivas e afetivas para atingir os objetivos de produção podem gerar hipersolicitação de suas funções psicofisiológicas (GASPARINI, BARRETO \& ASSUNÇÃO, 2005).

Para Dejours, Abdoucheli e Jayet (1994) as pressões resultantes da organização do trabalho podem desestabilizar a saúde mental. Enquanto as pressões ligadas às situações de trabalho têm com alvo principal o corpo dos trabalhadores, podendo provocar desgaste físico e doenças somáticas.

A partir deste fundamento teórico pode-se relacionar o sofrimento psíquico vivenciado pela mulher na atualidade, culminando com dor e adoecimento. É o que será abordado em seguida.

\section{Dor e somatização no contexto do trabalho feminino}

Pensar os efeitos da dor e da somatização na saúde das mulheres, implica pensar no lugar atribuído ao trabalho em nossa sociedade, a importância que este assume na produção da subjetividade e também nos modos de adoecer das trabalhadoras. E, além disso, tanto a dor quanto a somatização são doenças que não são visíveis, 
não sendo reconhecidas pelas outras pessoas (MERLO; VAZ; SPODE; ELBERN; KARKOW; VIEIRA, 2003).

Dejours (1992) expõe que as situações ansiogênicas geram condições de sofrimento e manifestações de somatização, quando o sujeito não é mais capaz de tratar mentalmente essas condições no trabalho. Sendo o trabalho feminino tão exigido, a mulher acaba desenvolvendo defesas egóicas inconscientes e, entre elas, está o fenômeno somático.

Assim, com todas essas exigências (ser mãe, profissional, dona de casa), a mulher se tornou angustiada, estressada e com profundas inquietações por ter absorvido tantos papéis, o que a deixou em instabilidade constante, manifestando, de diversas formas, seus conflitos psíquicos e, entre eles, encontramos a dor e somatização que aparecem como sintomas e sinais corporais de desequilíbrios psicossociais que estão ocorrendo ou podem vir a ocorrer associados à banalização da injustiça social e ao individualismo contemporâneo (DEJ OURS, 1999).

Salienta-se, ainda, como agravante à somatização, a fragilidade ou inexistência dos espaços de comunicação, expressão e transformação do sofrimento no trabalho em realização, prazer e saúde (DEJ OURS, 1999/2004).

Nesta direção, Ribeiro e Leda (2004) apontam que o trabalho deveria ser reconhecido como fonte de realização e de construção de identidade, mas está se mostrando, constantemente, como gerador de sofrimento e, em casos mais graves, até de adoecimento.

Portanto, o trabalho, quando perpassa a via do reconhecimento, contribui para a construção da identidade dos sujeitos, identidade esta responsável pela proteção da saúde mental. O sofrimento seria a inexistência de possibilidades, a limitação do ser humano a um estado de paralisia. Um risco que inviabiliza a construção da identidade e integridade dos sujeitos (OLIVEIRA, 2003).

Dejours (1992) aponta que o sofrimento psíquico sucedido da forma como o trabalho se organiza começa quando o trabalhador usou tudo que estava ao seu alcance em termos de conhecimento e de poder na organização do trabalho, e mesmo assim, ele não pode mais mudar nem sua tarefa, nem a forma como ela é feita.

Assim, pode-se considerar, conforme Oliveira (2003) que a organização do trabalho seja uma causa importante no aparecimento de algumas doenças. O conflito entre a organização do trabalho (com suas relações e regramentos) e a subjetividade do trabalhador é gerador de sofrimento psíquico, na medida em que o trabalhador tenta manter sua saúde mental, em meio a essa complexidade de relações. (DEJ OURS, 1999).

$\mathrm{E}$, tendo em vista o exposto, pode-se constatar que quando o sofrimento no trabalho não pode ser transformado em reconhecimento, surge a somatização como um sintoma deste 
sofrimento vivenciado no trabalho, manifestando-se no corpo (OLIVEIRA, 2003).

Azoubel Neto (2006) refere que a dor e a somatização manifestam-se no corpo feminino, tão exigido pelo trabalho, como estratégias de defesa no intuito de indicar que está havendo alguma condição de trabalho insuportável e que, no decorrer, poderá desorganizar este sujeito.

A mulher, atualmente, está passando por uma fase de transição e enfrentando inúmeras frustrações, pois se for traçado um perfil psicossocial da mesma, veremos que as mulheres das primeiras décadas do século XX tinham objetivos definidos - casar e ter filhosjá à mulher atual, tem suas funções maternais, uma vida profissional e ainda deve ter uma capacidade orgástica, exigência essa que não pesava na mulher do passado. Em decorrência, constata-se aumento gradual dos problemas funcionais e psicossomáticos em relação à maternidade e às funções sexuais femininas em geral (MELLO FILHO, 2002).

Nesta direção, é preciso distinguir até mesmo o fato de que nem sempre o sujeito reconhece seu sofrimento como sendo de ordem psíquica. E mesmo que o compreenda assim, muitas vezes não lhe concede a dimensão necessária para buscar ajuda. Assim, quando o faz, dificilmente associa seu sofrimento a situações laborais, mesmo porque, comumente, os problemas ditos pessoais ganham o direito de se manifestarem somente depois da jornada de trabalho (BORSOI, 2007).

No que se refere ao universo feminino, Heloani e Capitão (2003) apontam que o fenômeno somático afeta, principalmente, as trabalhadoras, das mais variadas atividades. Em geral, este não é facilmente diagnosticado, o que prejudica o processo de tratamento. Essa ocorrência maior de somatização em mulheres, não se relaciona somente às respostas biológicas, mas ao papel e à forma de inserção da mulher nas divisões social e sexual do trabalho (LEITE, SILVA \& MIRIGHI, 2007). A articulação saúde das mulheres e trabalho conta com um embate diferencial pela concentração de empregos precários devido à subvalorização e a exposição a múltiplos riscos, sobretudo por estes empregos (DEJ OURS, 1992).

Culturalmente, o papel feminino fixado é o da mulher como esposa, mas nos dias atuais, as mulheres estão avançando nas áreas de cultura e política. Por outro lado, as mulheres ainda têm um longo caminho a percorrer, pois até agora existem grandes distâncias entre homens e mulheres relacionados ao papel desta última na sociedade (SILVA, SANTOS, TEIXEIRA; LUSTOSA; COUTO; VICENTE; PAGOTTO, 2005). Assim, enquanto as atividades domésticas, geralmente atribuídas às mulheres, não são consideradas trabalho, pois se tratam apenas de atividades de manutenção das condições para a realização do autêntico trabalho, a desigualdade entre os sexos é 
perpetuada, causando maiores agravos à mulher trabalhadora (ROCHA \& DEBERT-RIBEIRO, 2001).

A saúde das mulheres trabalhadoras pode ser reconhecida como uma temática de pesquisa indispensável para o enriquecimento do campo de estudos na relação saúde/trabalho, uma vez que homens e mulheres são expostos a condições de trabalho diferenciadas no processo produtivo (BRITO \& D'ACRI, 1991).

A divisão sexual do trabalho, produzida pela organização do trabalho, impõe às mulheres uma jornada ilimitada a qual, associada a uma sobrecarga no trabalho doméstico e uma sobrecarga no trabalho remunerado, representa esforço excessivo, podendo contribuir para a deterioração progressiva da saúde dessas mulheres (BRITO, 2000).

Nos dias atuais, o que se apresenta são conflitos gerados por relações de trabalho que estão propiciando o aparecimento de doenças. Desta forma, quando não há espaço para a expressão deste conflito, o sintoma somático surge como uma válvula de escape das tensões psicológicas do indivíduo. Uma vida estressante parece influenciar nos casos de somatização feminina, fazendo com que haja uma maior predominância de eventos patogênicos na vida dessas mulheres (GAZZOTI \& CODO, 2002).

Com a entrada progressiva das mulheres no mercado de trabalho, começaram a surgir estudos sobre os efeitos do trabalho na saúde destas, não só do ponto de vista do comprometimento físico destas trabalhadoras como também pelos distúrbios psicoemocionais decorrentes de um sofrimento mental gerado pelo trabalho (AQUINO, MENEZES \& MARINHO, 1995).

As mudanças nas representações de feminilidade no século $X X$, juntamente com a atmosfera do movimento feminista, fizeram as mulheres buscarem fora do lar novas realizações, através do trabalho remunerado e independência familiar. Com isso, a mulher começou a buscar realizações intelectuais, lutar por ideais políticos, por se tornar uma profissional de sucesso, sem poder descuidar da estética (OLIVEIRA, 2003; MARIA FERNANDA \& COUTINHO, 2006; BORSOI, 2007).

\section{Considerações finais}

O trabalho, em nossa sociedade, assume importância na produção da subjetividade e, refletir sobre esse lugar atribuído ao trabalho, implica pensar nos efeitos sobre a saúde e, também nos modos de adoecer dos trabalhadores. Isso significa considerar a importância do trabalho e sua influência em todos os âmbitos do viver, considerando os aspectos subjetivos do trabalho e a sua centralidade enquanto elemento constituidor do indivíduo e da sua identidade. 
Ao falarmos em trabalho, é inevitável falarmos nas mulheres que, cada vez mais, vem adquirindo espaço no âmbito laboral e, desta forma, também sofrendo com as consequências desta inserção. Sendo assim, torna-se imprescindível considerar a questão de gênero na avaliação da saúde dos trabalhadores.

No atual contexto em que não interessa mais somente a força física, mas também a subjetividade do trabalhador, a mulher tem que conviver com o acúmulo de tarefas, ou seja, a dupla jornada de trabalho, onde concomitante ao trabalho remunerado também deve fazer o trabalho doméstico, e assim, ser trabalhadora, mãe, esposa e mulher. Todo esse esforço de conciliação pode deteriorar a saúde destas trabalhadoras, visto que não adquire a devida visibilidade.

Assim, ao mesmo tempo em que o trabalho é importante na vida e nas necessidades da mulher atual, também pode gerar sofrimento psíquico, causando problemas físicos e de ordem somática para a mesma, pois embora o trabalho deva ser algo prazeroso, que faz parte das realizações da vida da mulher, torna-se cada vez mais fonte de desorganização e desprazer.

Com a entrada, em escala crescente, das mulheres no mercado de trabalho, percebeu-se que, além do desgaste físico, esta poderia sofrer um desgaste mental em decorrência das exigências que the são impostas, resultando muitas vezes em sofrimento psíquico, podendo levar a sintomas somáticos.

Desta forma, podemos perceber que a dor e a somatização se manifestam no corpo feminino para indicar que está havendo algum sofrimento não conciliável com a organização de trabalho, sofrimento este que, muitas vezes, nem é percebido como sendo de ordem psíquica ou deflagrado pela sua relação patogênica com o trabalho. E, ainda que assim o perceba, dificilmente concede a atenção necessária aos aspectos subjetivos, banalizando o sofrimento vivenciado e naturalizando o excesso de trabalho.

Para finalizar, expressamos nosso desejo de que este estudo possa ter despertado para uma reflexão sobre os pensamentos, os sentimentos e a realidade das mulheres que através da dor, enquanto somatização, denunciam que está havendo alguma condição de trabalho insuportável e que, no decorrer, poderá desorganizá-las. Neste contexto, nós, enquanto psicólogos, temos um longo trabalho de escuta da organização de trabalho e de seus autores e atores, a fim de possibilitar que a rigidez organizacional ceda espaço para a expressão da inteligência e da criatividade da mulher, bem como, o reconhecimento de sua contribuição, no intuito de que o sofrimento encontre sentido e não precise transformar-se em dor.

Desta forma, estaremos contribuindo na promoção de relações de trabalho mais éticas, mais humanas e, consequentemente, mais saudáveis para a mulher que é uma das grandes protagonistas desta 
história, a fim de possibilitar que a rigidez organizacional possa ceder espaço ao reconhecimento.

\section{Referências}

AQUINO, E. M. L.; MENEZES, G. M. S.; MARINHO, L. F. B. Women, health, and labor in Brazil: challenges for new action. Cadernos de Saúde Pública, Rio de Janeiro, v. 11, n. 2, 1995.

AZOUBEL NETO, D. A psicanálise do processo primário: reflexões sobre a metapsicologia da dor. Revista da SPAGESP, Ribeirão Preto, v.7, n. 1, p. 28-43, 2006.

BORSOI, I. C. F. Da relação entre trabalho e saúde à relação entre trabalho e saúde mental. Psicologia \& Sociedade, Porto Alegre, v. 19, n. especial, pp. 103-111, 2007.

BRANT, L. C.; MINAYO-GOMEZ, C. A transformação do sofrimento em adoecimento: do nascimento da clínica à psicodinâmica do trabalho. Ciência \& Saúde Coletiva, Rio de Janeiro, v. 9, n. 1, pp. 213223, 2004.

BRITO, J. C.; D'ÁCRI, V. Referencial de Análise para o Estudo da Relação Trabalho, Mulher e Saúde. Cadernos de Saúde Pública, Rio de Janeiro, v. 7, n.2, p. 201-214, 1991.

BRITO, J. C. Enfoque de gênero e relação saúde/trabalho no contexto de reestruturação produtiva e precarização do trabalho. Cadernos de Saúde Pública, Rio de Janeiro, v. 16, n. 1, p. 195-204, 2000. COELHO, C. L. S.; AVILA, L. A. Controvérsias sobre a somatização. Revista Psiquiatria Clínica, São Paulo, v. 34, n. 6, p. 278-284, 2007.

DEJOURS, C.; ABDOUCHELI, E.; JAYET, C. Psicodinâmica do trabalho: contribuições da Escola Dejouriana à análise da relação prazer, sofrimento e trabalho. São Paulo: Atlas, 1994.

DEJ OURS, C. A loucura do trabalho: estudo de psicopatologia do trabalho. São Paulo: Cortez, 1992.

. Psicodinâmica do trabalho. São Paulo: Atlas, 1994.

A Banalização da injustiça social. Rio de Janeiro: Fuñāação Getúlio Vargas, 1999.

.Addendum. IN: LANCMAN, S. \& SZNELWAR, L. I. Christophe

Dejours: da psicopatologia à psicodinâmica do trabalho. Rio de Janeiro: Editora Fiocruz, Brasília: Paralelo 15, $2004 a$.

. Prefácio. IN: LANCMAN, S. \& SZNELWAR, L. I. Christophe Dejours: da psicopatologia à psicodinâmica do trabalho. Rio de Janeiro: Editora Fiocruz, Brasília: Paralelo 15, 2004b.

FONSECA, T. M. G. Gênero, subjetividade e trabalho. Rio de J aneiro: Vozes, 2000. 
GASPARINI, S. M.; BARRETO, S. M.; ASSUNÇÃO, A. A. O professor, as condições de trabalho e os efeitos sobre sua saúde. Educação e Pesquisa, São Paulo, v. 31, n. 2, p. 189-199, 2005.

GAZZOTTI, A. A.; CODO, W. Histeria: doença profissional. In: JACQUES, M. G. \& CODO, W. Saúde mental \& trabalho: leituras. Rio de Janeiro: Vozes, 2002.

GIL, A. C. Como elaborar projetos de pesquisa. 4. ed. São Paulo: Atlas, 2002.

HELOANI, J. R.; CAPITAO, C. G. Saúde mental e psicologia do trabalho. São Paulo Perspectiva, São Paulo, v. 17, n. 2, p. 102108, 2003.

HELOANI, R.; LANCMAN, S. Psicodinâmica do trabalho: o método clínico de intervenção e investigação. Produção, São Paulo, v. 14, n. 3, p. 77-86, 2004.

LAKATOS, E. M. Metodologia do trabalho científico: procedimentos básicos, pesquisa bibliográfica, projeto e relatório, publicações e trabalhos científicos. 2. ed. São Paulo: Atlas, 1986.

LANCMAN, S.; UCHIDA, S. Trabalho e subjetividade: o olhar da psicodinâmica do trabalho. Cadernos de Psicologia Social do Trabalho, v. 6, não consta número, p. 79-90, 2003.

LEITE, P. C.; SILVA, A.; MERIGHI, M. A. B. A mulher trabalhadora de enfermagem e os distúrbios osteomusculares relacionados ao trabalho. Revista da Escola de Enfermagem - USP, São Paulo, v. 41, n. 2, p. 287, 291, 2007.

MARIA FERNANDA, D.; COUTINHO, M. C. A dialética da inclusão/exclusão e o trabalho feminino. Interações, v. 11, n.21, p. 121-142. 2006.

MARTINS, J. C. O.; PINHEIRO, A. A. G. Sofrimento psíquico nas relações de trabalho. Psicologias, v. 7, n. 1, p. 79-85, 2006.

MELLO FILHO, J. Concepção psicossomática: visão atual. 9. ed. São Paulo: Casa do Psicólogo, 2002.

MENDES, A. M. Comportamento defensivo: uma estratégia para suportar o sofrimento no trabalho. Revista de Psicologia da UFC, Ceará, v. 13-14, n. 1-2, p. 27-32, 1996.

MENDES, A. M. Cultura organizacional e prazer e sofrimento no trabalho: uma abordagem psicodinâmica. IN: TAMAYO, A. (org.).

Cultura e saúde nas organizações. Porto Alegre: Artmed, 2004.

MERLO, A. R. C.; VAZ, M. A.; SPODE, C. B.; ELBERN, J. L. G.; KARKOW, A. R. M.; VIEIRA, P. R. B. O trabalho entre prazer, sofrimento e adoecimento: a realidade dos portadores de lesões por esforços repetitivos. Psicologia \& Sociedade, Belo Horizonte, v. 15, n. 1, p. 117-136. 2003.

MERLO, A. R. C. Saúde e trabalho no Rio Grande do Sul. Porto Alegre: Editora UFGRS, 2004. 
NOGUEI RA, M. C. O. C. Os discursos das mulheres em posições de poder. Cadernos de Psicologia Social do Trabalho, v. 9, n. 2, p. 57-72, 2006.

OLIVEIRA, N. T. Somatização e sofrimento no trabalho. Revista Virtual Textos \& Contextos, v. 9, n. 2, ano II, p. 1-14, 2003.

RIBEIRO, C. V. S.; LEDA, D. B. O significado do trabalho em tempos de reestruturação produtiva. Estudos e Pesquisas em Psicologia, Rio de Janeiro, v. 4, n. 2, p. 76-83, 2004.

ROCHA, L. E.; DEBERT-RIBEIRO, M. Trabalho, saúde e gênero: um estudo comparativo sobre analistas de sistemas. Revista Saúde Pública, São Paulo, v. 35, n. 6, p. 539-47, 2001.

SILVA, G. C. C.; SANTOS, L. M.; TEIXEIRA, L. A.; LUSTOSA, M. A.; COUTO, S. C. R; VICENTE, T. A.; PAGOTTO, V. P. F. A mulher e sua posição na sociedade: da antiguidade aos dias atuais. Revista SBPH, Belo Horizonte, v. 8, n. 2, p. 65-76, 2005.

\section{Endereço para correspondência}

Rubia Minuzzi Tschiedel

Avenida França, 841, 301. Bairro Bela Vista. CEP 95076-000. Caxias do Sul, RS, Brasil

Endereço eletrônico: rubia_tschiedel@yahoo.com.br

Elisete Soares Traesel

Rua Tenente Fraga, 138. Bairro Presidente J oão Goulart. Santa Maria, RS, Brasil.

Endereço eletrônico: elisetetraesel@unifra.br

Recebido em: 28/05/2012

Reformulado em: 30/05/2013

Aceito para publicação em: 11/06/2013

Acompanhamento do processo editorial: Deise Mancebo

\section{Notas}

* Graduada em Psicologia pelo Centro Universitário Franciscano (Santa Maria, RS, Brasil) e Mestre em Psicologia Clínica pela UNISINOS - Universidade do Vale do Rio dos Sinos (São Leopoldo, RS, Brasil).

**Graduada em Psicologia pela Universidade Regional do Noroeste do Estado do Rio Grande do Sul (Ijuí, RS, Brasil), Mestre em Psicologia Social e Institucional pela UFRGS - Universidade Federal do Rio Grande do Sul (Porto Alegre, RS, Brasil), Doutoranda em Psicologia Social e Institucional pela UFRGS - Universidade Federal do Rio Grande do Sul (Porto Alegre, RS, Brasil) e Docente do Centro Universitário Franciscano (Santa Maria, RS, Brasil). 